\title{
Initial experience with ocriplasmin in the treatment of vitreomacular traction
}

\section{Experiência inicial com ocriplasmina no tratamento da tração vitreorretiniana}

\author{
José Maurício Botto de Barros Garcia ${ }^{1,2}$, David Leonardo Cruvinel Isaac ${ }^{1,2}$, Marcos Ávila ${ }^{1,2}$
}

\begin{abstract}
This study aimed to report the clinical and structural outcomes of intravitrea ocriplasmin in the treatment of vitreomacular interface disorders in two tertiary centers in Brazil. A retrospective study was performed by reviewing medical records and spectral domain optical coherence tomography (SD-OCT) findings of seven patients who were treated with a single ocriplasmin injection. A total of $57.14 \%$ of patients achieved resolution of vitreomacular traction as evidenced by SD-OCT. Regarding our functional results, $87.71 \%$ maintained or improved visual acuity after follow-up. To the best of our knowledge, this is the first study reporting initial results of ocriplasmin therapy in Brazil.
\end{abstract}

Keywords: Vitreous body/pathology; Fibrinolytic agents/therapeutic use; Fibrinolysin/therapeutic use; Tomography, optical coherence; Tertiary care centers

\section{RESUMO}

O objetivo desse estudo é relatar os resultados iniciais, tanto do ponto de vista funcional quanto anatômico, no tratamento das doenças da interface vítreo-macular com a ocriplasmina em 2 serviços terciários no Brasil. Um estudo retrospectivo foi realizado através de revisão de prontuários, além de análise de achados em tomografia de coerência óptica de domínio espectral (SD-OCT) em 7 pacientes tratados com uma única injeção intravítrea de ocriplasmina. Em nosso estudo 57,14\% dos pacientes apresentaram resolução da tração vítreo-macular no SD-OCT. Em relação aos resultados funcionais, $87,71 \%$ dos pacientes mantiveram, ou melhoraram sua acuidade visual durante o acompanhamento. Para nosso conhecimento, trata-se do primeiro estudo em nosso país, mostrando resultados iniciais com ocriplasmina em pacientes tratados no Brasil.

Descritores: Corpo vítreo/patologia; Fibrinolíticos/uso terapêutico; Fibronilisina/uso terapêutico; Tomografia de coerência óptica; Centros de atenção terciária

\section{INTRODUCTION}

Anomalous posterior vitreous detachment (PVD) is a pathological variant of the aging gel liquefaction process ${ }^{(1,2)}$. In this variant, the vitreous gel adheres in an abnormally strong manner to the retina. Combining the current knowledge regarding PVD with advances in optical coherence tomography (OCT), a panel of specialists convened to develop a consensus classification of vitreomacular interface (VMI) disorders ${ }^{(3)}$, such as vitreomacular adhesion (VMA), vitreomacular traction (VMT), and partial or full thickness macular hole $(\text { FTMH) })^{(3,4-6)}$.

VMA occurs during initial and partial PVD, when a portion of the posterior vitreous remains attached to the macula without alterating the underlying retinal contour ${ }^{(4)}$. VMA may develop into VMT, with subsequent symptom development and anatomical distortion observed on OCT. This continuous traction may progress to FTMH or other potentially sight-threatening conditions ${ }^{(4-6)}$.

In general, observation and pars plana vitrectomy have been the only treatment options for vitreomacular interface disorders. The Microplasmin for Intravitreous Injection-Traction Release without Surgical Treatment (MIVI TRUST) program, comprising two randomized clinical trials, demonstrated the benefits of a single $0.125-\mathrm{mg}$ intravitreal ocriplasmin injection (JETREA; ThromboGenics, USA). Good tolerability and higher nonsurgical resolution of VMA were observed in 464 patients who were administered ocriplasmin (26.8\%) than in 188 control patients who were administered the placebo $(10.1 \%)^{(4,6)}$. Supported by this data, in 2012, the US Food and Drug Administration approved pharmacological vitreolysis as a valid therapeutic alternative for symptomatic VMA ${ }^{(5)}$. Ocriplasmin is a recombinant, truncated form of the human plasmin with autolytic and proteolytic activity. It mainly targets fibronectin and laminin that are abundant in vitreous gel and provides in a normal condition, a suitable attachment to the retina ${ }^{(6-8)}$. The resolution of VMA has been typically observed within 28 days of ocriplasmin injection ${ }^{(4,6)}$. The treatment also induced higher rates of FMTH closure (40.6\%) compared with the sham group $(10.6 \%)^{(4)}$. The MIVI TRUST study group results demonstrated major benefits in patients younger than 65 years, with focal adhesions (diameter $\leq 1500 \mu \mathrm{m}$ ), absence of epiretinal membrane, and phakic lens status ${ }^{(4)}$. In this case series, we report the initial experience of intravitreal ocriplasmin in the treatment of symptomatic VMA in Brazil.

\section{METHODS}

This study was a retrospective analysis of a small case series of seven patients who were diagnosed with VMT according to the International VitreomacularTraction study group and who were treated with ocriplasmin at the Centro Brasileiro de Cirurgia de Olhos (Goiânia, GO) and Centro Brasileiro da Visão (Brasília, DF) in 2013 and 2014 $4^{(3)}$. Spectral domain OCT (SD-OCT) was performed using Spectralis (Heidelberg Engineering; Heidelberg, Germany). Following informed consent, a single 0.125 -mg ocriplasmin injection was administered under sterile conditions. Snellen best-corrected visual acuity (BCVA) values were converted to logMAR units ${ }^{(9)}$. 


\section{RESULTS}

Patient data are shown in table 1. The subjects had a median age of 66.14 years. Six patients (85.71\%) were females. Initial and final BCVA measurements ranged from 0.19 to 0.17 , respectively, after a median follow-up of 70.57 days. Overall, 4 patients (57.14\%) achieved anatomical resolution (Figures 1 and 2). Three patients (42.8\%) were older than 65 years. One of these three patients achieved VMT release during follow-up. All members included in this study were diagnosed with VMA or VMT, and none of them presented with epiretinal membrane or FTMH. Studying the 3 patients who failed to achieve anatomical resolution, one patient exhibited a decrease in BCVA (Figure 3), 3 presented brief metamorphopsia, and one demonstrated transient conjunctival hemorrhage, flashes, and diplopia. No post-injection endophthalmitis or retinal tears were identified.

Table 1. Demographical and clinical characteristics of the study population

\begin{tabular}{|c|c|c|c|c|c|c|c|c|c|c|c|c|c|c|}
\hline Patient & Sex & Age & Eye & $\begin{array}{c}\text { Lens } \\
\text { status }\end{array}$ & ERM & MH & $\begin{array}{l}\text { Focal } \\
\text { VMT }\end{array}$ & $\begin{array}{c}\text { Broad } \\
\text { VMT }\end{array}$ & $\begin{array}{c}\text { Initial } \\
\text { BCVA } \\
\text { (logMAR) } \\
\end{array}$ & $\begin{array}{c}\text { Final } \\
\text { BCVA } \\
\text { (logMAR) } \\
\end{array}$ & $\begin{array}{c}\text { Initial } \\
\text { BCVA } \\
\text { (Snellen) } \\
\end{array}$ & $\begin{array}{c}\text { Final } \\
\text { BCVA } \\
\text { (Snellen) } \\
\end{array}$ & $\begin{array}{l}\text { Follow up } \\
\text { in days }\end{array}$ & $\begin{array}{c}\text { VMT } \\
\text { resolution } \\
\text { (SD-OCT) }\end{array}$ \\
\hline 1 & $\mathrm{~F}$ & 49 & OS & Phakic & - & - & + & - & 0.30 & 0.18 & $20 / 40$ & $20 / 30$ & 28 & + \\
\hline 3 & $\mathrm{~F}$ & 62 & $O D$ & PCIOL & - & - & + & - & 0.18 & 0.00 & $20 / 30$ & $20 / 20$ & 40 & + \\
\hline 4 & F & 79 & OS & PCIOL & - & - & + & - & 0.30 & 0.30 & $20 / 40$ & $20 / 40$ & 61 & - \\
\hline 7 & $\mathrm{~F}$ & 64 & OS & PCIOL & - & - & + & - & 0.18 & 0.18 & $20 / 30$ & $20 / 30$ & 14 & + \\
\hline
\end{tabular}

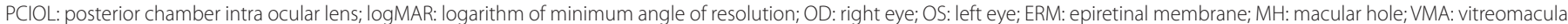
adhesion; VMT: vitreomacular traction; SD-OCT: spectral domain optical coherence tomography.
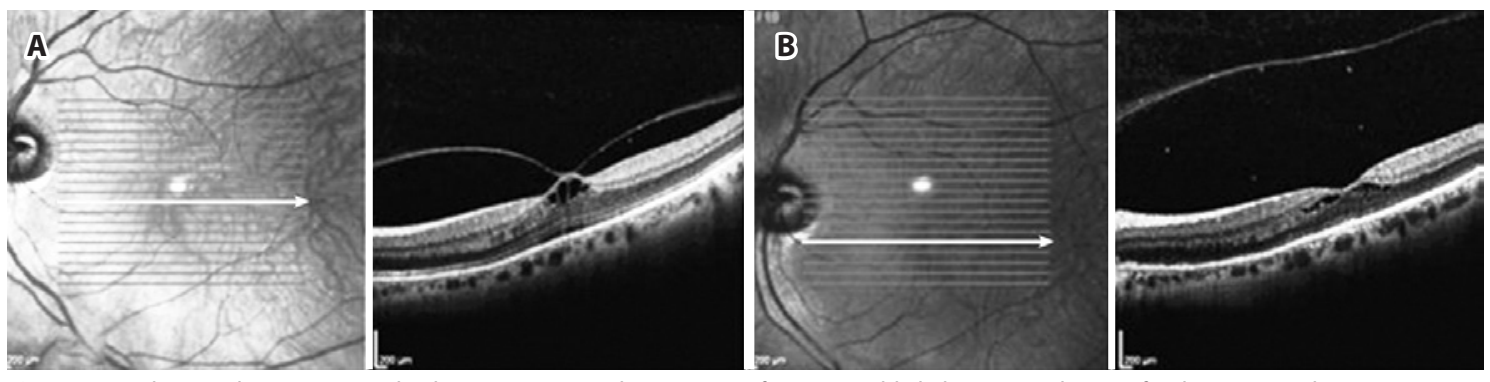

Figure 1. Initial Spectral Domain Optical Coherence Tomography (SD-OCT) of a 49-year-old phakic patient showing focal vitreo-macular traction (VMT) (A), with complete separation of the posterior hyaloid 4 days after ocriplasmin injection, accompanied by re-establishment of macular contours (B).
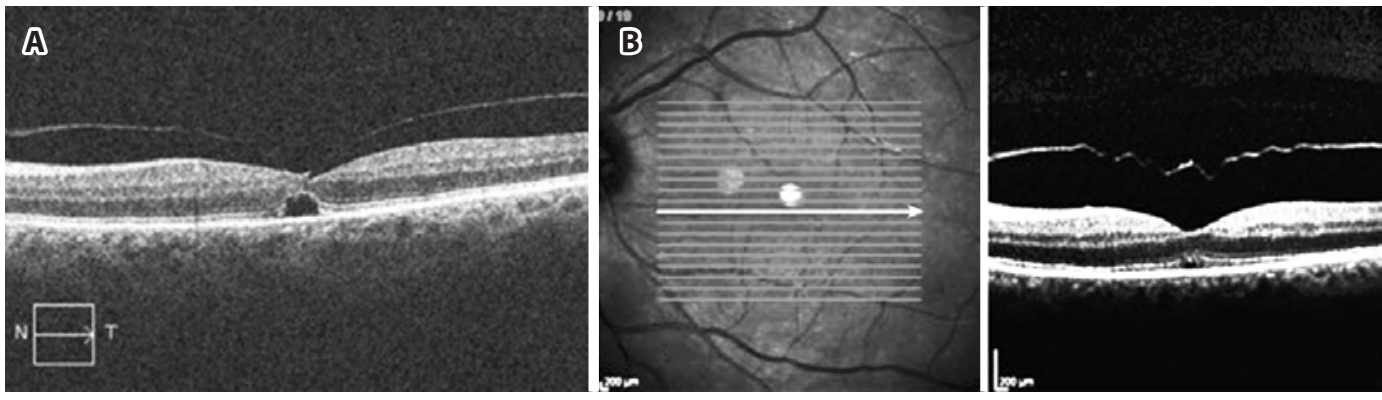

Figure 2. A 64-year-old patient having focal vitreo-macular traction (VMT) with subretinal fluid as observed on Cirrus Spectral Domai Optical Coherence Tomography (SD-OCT) (Carl Zeiss Meditec, USA), which was clinically managed over 58 days (A); 14 days after ocriplasmin injection, retinal anatomy was re-established (B).
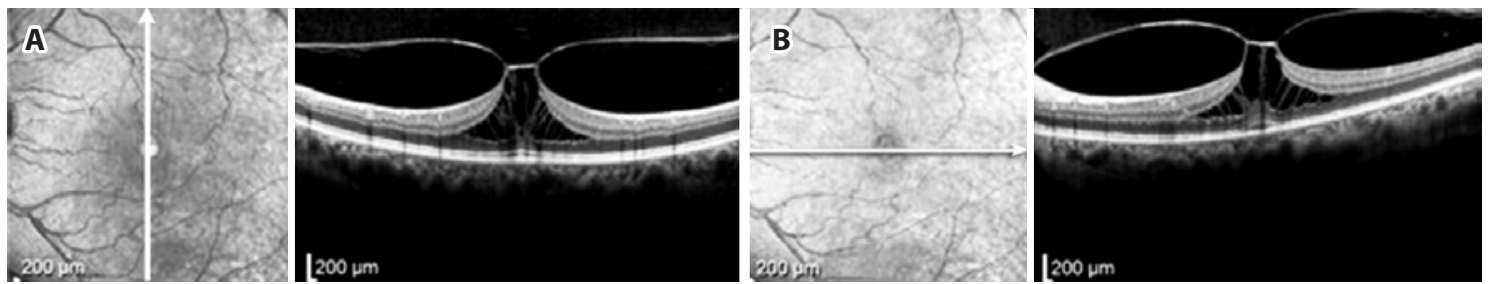

Figure 3. A 63-year-old patient complained about significant metamorphopsia (A). Spectral Domain Optical Coherence Tomography (SD-OCT) showed persistent focal vitreo-macuolar traction (VMT), with no reported fracture in the ellipsoid segment (IS/OS) of the outer retina during the follow-up period (B); the patient experienced loss of vision from 20/20 to 20/50. 


\section{DISCUSSION}

Pharmacological vitreolysis has been studied as an alternative to vitrectomy and has become a promising medical agent because of its ability to induce PVD, for its stable structure, and as a supplement to observation and vitrectomy in managing selected disorders ${ }^{(5-8,10)}$. Previous studies have demonstrated that appropriate patient selection is critical for improving outcomes using ocriplasmin ${ }^{(5-8,10)}$.

The overall frequency of successful release (4 eyes, 57.1\%) was higher in this study than in phase III clinical trials (26.5\%). Three patients (42.8\%) from our series were older than 65 years, which has been related to a worse prognosis following pharmacological vitreolysis( ${ }^{(4)}$. Kim et al. ${ }^{(5)}$, after studying a carefully selected group of 19 patients, demonstrated a separation of VMT in $42 \%$ of the patients. In a sample size of 17 patients, Singh et al. ${ }^{(7)}$ reported a $47.1 \%$ resolution rate within 28 days after the injection; although this group reported predictive factors and patient enrollment similar to those reported by the MIVI TRUST group ${ }^{(4)}$, they used SD-OCT instead of time domain OCT, which has an inferior resolution.

According to Singh et al. ${ }^{(7)}$, almost all patients who responded to therapy had outer retinal fracture in the ellipsoid zone (IS/OS junction) as observed on SD-OCT, which was probably because of the potential toxicity of the drug. Nevertheless, this did not alter the study outcomes regarding the spontaneous resolution of the symptoms or SD-OCT findings, with treatment response occurring in most patients within the first 7 days after the procedure, with further improvement during follow-up. In our group, four patients initially complained of blurred vision or reduced BCVA in the initial observation after the injection; however, no evident outer retina abnormalities could be observed on SD-OCT.

The limitations of our study include the small sample and its retrospective design. A retrospective study, which was performed with eight patients, revealed complete resolution in $62.5 \%$ after a minimum period of 1 month of observation, corroborating our results $^{(8)}$. It is important to highlight that this study included only a small case series, and these results cannot be directly compared with randomized clinical trials. To the best of our knowledge, this is the first study reporting the initial data on pharmacological therapy of VMl-related diseases in Brazil.

In conclusion, in our study, 4 of 7 seven eyes achieved anatomical resolution of VMT after a single 0.125 -mg ocriplasmin injection. This corroborates with phase III clinical trials that have proved the benefits of ocriplasmin, leading to a shift in treatment paradigm with respect to achieving optimal outcomes in symptomatic patients. Future and larger reports, particularly with SD-OCT, should help us understand and better explain the drug's mechanism of action.

\section{REFERENCES}

1. Warrow DJ, Lai MM, Patel A, Raevis J, Berinstein DM. Treatment outcomes and spectral-domain optical coherence tomography findings of eyes with symptomatic vitreomacular adhesion treated with intravitreal ocriplasmin. Am J Ophthalmol. 2015; 159(1):20-30ea.

2. Xu LT, Punjabi OS, Shao J, Ehlers JP, Srivastava SK, Singh RP, et al. Frequency of vitreomacular interface disease in patients presenting to a tertiary care institution. Ophthalmic Surg Lasers Imaging Retina. 2014;45(6):517-20.

3. Duker JS, Kaiser PK, Binder S, de Smet MD, Gaudric A, Reichel E, et al. The International Vitreomacular Traction Study Group. Classification of vitreomacular adhesion, traction, and macular hole. Ophthalmology. 2013;120(12):2611-9.

4. Stalmans P, Benz MS, Gandorfer A, Kampik A, Girach A, Pakola S; et al, for the MIVI-TRUST Study Group. Enzymatic vitreolysis with ocriplasmin for vitreomacular traction and macular hole. N Engl J Med. 2012;367(7):606-15.

5. Kim BT, Schwartz SG, Smiddy WE, Doshi RR, Kovach JL, Berrocal AM, et al. Initial outcomes following intravitreal ocriplasmin for treatment of symptomatic vitreomacular adhesion. Ophthalmic Surg Lasers Imaging Retina. 2013:44(4):334-43.

6. Kuppermann BD. Ocriplasmin for pharmacologic vitreolysis. Retina. 2012;32 Suppl 2:S225-8; discussion S228-31.

7. Singh RP, Li A, Bedi R, Srivastava S, Sears JE, Ehlers JP, et al. Anatomical and visual outcomes following ocriplasmin treatment for symptomatic vitreomacular traction syndrome. Br J Ophthalmol. 2014;98(3):356-60.

8. Knudsen VM, Kozak I. A retrospective study of a single practice use of ocriplasmin in the treatment of vitreomacular traction. Saudi J Ophthalmol. 2014;28(2):139-44.

9. Gregori NZ, Feuer W, Rosenfeld PJ. Novel method for analyzing snellen visual acuity measurements. Retina. 2010;30(7):1046-50.

10. de Smet MD, Jonckx B, Vanhove M, van Calster J, Stalmans P, Stassen JM. Pharmacokinetics of Ocriplasmin in Vitreous. Invest Ophthalmol Vis Sci. 2012;53(13):8208-13. 